\title{
Promoting Healthy Relationship Development in Teens, Part II: Three Key Qualities to Foster Better Relationships ${ }^{1}$
}

\author{
Victor W. Harris, Gilon Marts, and Muthusami Kumaran²
}

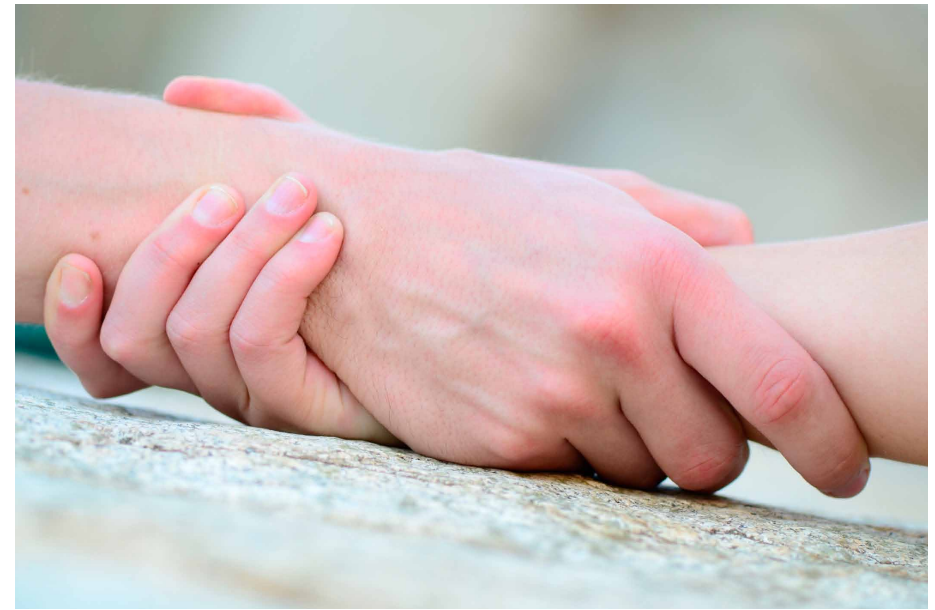

Figure 1. Relationships and marriages where both partners are kind, nurturing, affectionate, sympathetic, and caring tend to be more satisfying.

Credits: http://www.thinkstock.com

A Google search inquiring about lasting relationships reveals a variety of interesting notions, such as Erich Fromm's humorous insight: "True love is like a pair of socks: you've gotta have two and they've gotta match." So goes one of the many philosophies about what it takes to find and maintain lasting love and relationships.

Despite his somewhat cavalier approach to the subject, Erich Fromm was right-couples who stay together tend to match and be more similar than they are different. It is these similarities and differences that often impact how well two people in a romantic relationship are able to communicate and interact with each other. In addition, each person also brings background influences into the relationship such as family of origin habits and processes. Individual characteristics also exert a certain amount of influence on the couple's functioning as a whole. These components are further examined below.

\section{Helpful Information}

\section{Three Kinds of Premarital Predictors}

Jeffry Larson and Thomas Holman have conducted the most long-term and specific studies of the premarital predictors of healthy marriages (Larson and Holman 1994; Holman 2001; Larson 2003). They have synthesized these premarital predictors into three general areas: 1 ) background and contextual factors; 2 ) individual traits and behaviors; and, 3) interactional processes-effective communication and conflict resolution. While any number of factors may show some predictive reliability and validity, these three areas, interactional processes, individual traits and behaviors, and background and contextual factors, tend to be the most indicative of future marital quality, stability, and satisfaction.

1. This document is FCS2326, one of a series of the Family Youth and Community Sciences Department, Florida Cooperative Extension Service, Institute of Food and Agricultural Sciences, University of Florida. Original publication date March 2013. Visit the EDIS website at http://edis.ifas.ufledu.

2. Victor W. Harris, assistant professor and family life education Extension specialist, Department of Family, Youth and Community Sciences; Gilon Marts, student, Department of Family, Youth and Community Sciences; and Muthusami Kumaran, assistant professor, Department of Family, Youth and Community Sciences; University of Florida; Gainesville, FL 32611. 
Understanding the value of how similar backgrounds, traits, and healthy interactional processes can increase the stability of a marriage is important for at least two reasons: First, because low-resource families tend to experience higher levels of stresses and strains compared to high-resource families, they are particularly vulnerable to negative interactional processes that can disrupt functional family patterns and marital relationships (Harris et al. 2012; Schramm et al. 2011). Second, understanding the value of these factors makes it clear that researchers, educators, and practitioners must focus at least part of human services programming for both low-resource and high-resource dating couples on healthy interaction and conflict resolution processes specific to individual contexts and differences. John Gottman's nine communication skills (the four don'ts: criticism, contempt, defensiveness, and stonewalling, and the five do's: calm down, complain, speak non-defensively, validate, and overlearn skills), for example, are some of the most empirically informed and researchtested communication skills available to help dating and married couples learn to interact effectively and to resolve conflict successfully (Gottman 1994a and 1994b; Hillsdale et al. 1998; Gottman, Katz and Hooven 1997; Gottman and Levenson 1999 and 2000).

\section{Background and Contextual Factors}

Family of Origin Influences. The family of origin is the family a person grows up in. The conditions of the home environment including the quality of parents' marriages and parent-child interactions has consistently been shown to influence the quality of adult children's choices within premarital relationships, marriages, and family life. Growing up in a low-resource home, a single-parent home, or a home in which parents divorced, for example, can put adult children at greater risk for marital dissolution (Larson and Holman 1994; Holman 2001; Larson 2003). Additionally, family of origin factors such as toxic or healthy cognitive, emotional, or behavioral patterns, mental illness, how effectively parents and friends express themselves while communicating their approval of dating and potential marriage partners, enmeshment with or autonomy from the family, school/work stress and related spillover, debt, health, and functional and dysfunctional interactions with family members, can each exert an influence on dating relationships and future marital quality, stability, and satisfaction (Larson and Holman 1994; Holman 2001; Larson 2003).

Sociocultural Factors. Sociocultural factors include demographic factors such as age at marriage, levels of education and income, gender differences, race/ethnicity, social class, and employment/occupation (Larson and Holman 1994;
Holman 2001; Larson 2003). Early age at marriage, for example, is consistently associated with marital instability and poverty, especially for women. Higher levels of education, income, and employment are generally more predictive of higher marital stability and satisfaction. Race/ ethnicity, class, and socioeconomic status have shown mixed results in predicting marital quality outcomes (Larson and Holman 1994; Holman 2001; Larson 2003; Karney et al. 2007; Amato et al. 2003; Dahl 2010; National Fatherhood Initiative 2005; Johnson et al. 2002; Schramm et al. 2003; Harris et al. 2012).

\section{Individual Traits and Behaviors}

Gender is not a reliable predictor of marital outcomes. However, across genders there are some personality and mental health traits and behaviors that tend to be liabilities or assets for future marital quality, stability, and satisfaction. Relationships and marriages where both partners are less traditional and are more androgynous (e.g., kind, nurturing, affectionate, sympathetic, caring) tend to be more satisfying (Karney et al. 2007; Amato et al. 2003; Dahl 2010; National Fatherhood Initiative 2005; Johnson et al. 2002; Schramm et al. 2003; Harris et al. 2012; Larson and Holman 1994; Holman 2001; Larson 2003). Some individual trait and behavior liabilities that can potentially wield a negative influence on marital quality, stability, and satisfaction include difficulties managing stress, impulsiveness, selfconsciousness, unregulated anger and hostility, untreated depression and other mental health disorders, chronic irritability, and dysfunctional beliefs, such as those inherent within the following marriage myths:

- "No matter how I behave, my spouse should love me simply because she is my spouse."

- "If my spouse loves me, he should instinctively know what I want and need to be happy."

- "I can change my spouse by pointing out his inadequacies, errors, and other flaws."

- "I must feel better about my partner before I can change my behavior toward him."

- "Maintaining romantic love is the key to marital happiness over the life-span for most couples."

- "Marriage should always be a 50-50 partnership."

- "Marriage can fulfill all of my needs." (Larson 2003) 
Assets include individual traits and behaviors such as being an extrovert, flexible, adaptable and/or assertive. Exhibiting high levels of self-esteem, commitment, and an ability to love others are additional assets found to be predictive of healthy relationships and marriages (Larson and Holman 1994; Holman 2001; Larson 2003).

Low-resource populations can be particularly vulnerable to reduced assets and increased liabilities because of the additional stressors and strains they experience. However, the presence of the aforementioned assets can serve to bolster their resilience in managing stressors commonly experienced in low-resource households.

\section{Interactional Processes}

Healthy couple relationships in marriage are established through healthy interactional processes that evolve during dating. Research indicates that it is the similarities (e.g., values, beliefs, interests) among romantic partners, not the differences, that are most likely to predict marital quality, stability, and satisfaction (Murstein 1986; Karney et al. 2007).

For example, in Paths to Marriage, psychologist B. I. Murstein has identified the stage-like process of how friendship can lead to romance in what he calls the $S V R$ - Stimulus-Values-Roles filtering process that couples tend to experience. In the stimulus stage, couples are attracted to each other. In the values stage, couples analyze each other's values and beliefs to determine whether they are similar to or different from their own. In the roles, or final, stage, couples determine how various roles (e.g., traditional or androgynous, division of labor, religious, etc.) will be enacted and maintained in the relationship and whether or not the fulfillment of these roles will promote an enduring friendship. Couples determine partner-compatibility in each of these stages through filtering out potential partners who don't match up to their criteria (Murstein 1986).

The results appear to be mixed with regard to whether or not marital quality tends to be higher for couples who are similar in race, socioeconomic status, intelligence, age, and/or religiosity. However, it is easy to see how differing values, beliefs, and interests could lead to potential marital conflicts in any of these areas (Larson and Holman 1994; Holman 2001; Larson 2003; Mahoney et al. 2001).

Interactional History and Processes. Interactional history (i.e., acquaintance, premarital sex, premarital pregnancy, cohabitation, dating violence) and processes (i.e., communication, conflict, consensus building) are some of the more important predictors of marital quality, stability, and satisfaction (Larson and Holman 1994; Holman 2001; CDC 2012). It makes sense that developing a deeper acquaintance and friendship before marriage would be associated with higher marital quality given the importance of maintaining friendship in marriage. Additionally, higher rates of premarital sexual experience with multiple partners have been linked to extramarital sex, which is a predictor of lower marital stability and divorce. However, research indicates that having a monogamous sexual relationship with only the eventual marriage partner prior to marriage is not necessarily associated with a higher risk of divorce (Larson and Holman 1994; Holman 2001; Teachman 2003). Premarital childbearing tends to be accompanied by a number of potentially difficult decisions (Miller 1993). It has also been linked to higher rates of divorce, especially in the early years of marriage and is more pronounced among whites than among blacks. However, premarital conceptions do not in and of themselves predict divorce (Larson and Holman 1994; Holman 2001). A higher than normal percentage of teen pregnancies, for example, are miscarried (Miller 1993).

The fact that cohabitation has become a stage in the dating process has definitely led to an increase in the research about how cohabitation influences future marriage relationships. Although many who cohabit eventually marry, cohabitation has been significantly associated with lower levels of marital interaction, higher rates of divorce proneness (i.e., thoughts of divorce), and decreased commitment to life-long marriage (Amato et al. 2003; Smock 2000; Larson and Holman 1994). There is growing evidence that some who choose to cohabit may enter their cohabitating relationships with lower levels of commitment to begin with and that the actual act of cohabitation can alter future commitment levels (Marshal et al. in press; Larson and Holman 1994; Brines and Joyner 1999; Whitehead and Popenoe 2000). In order to avoid the risks and responsibilities associated with cohabitation, some couples are engaging in a growing trend toward "stayover relationships" at a romantic partner's place up to several nights a week (Jamison and Ganong 2011). This, they perceive, allows them the flexibility to live their own lives without the inconveniences and commitments of living together.

With respect to the impact of cohabitation on children, the movement of mothers into and out of cohabiting relationships significantly increases the likelihood of family instability for children, as well as poverty and other hardships. Married parents with children tend to have higher incomes than single parents or cohabiting couples with children. 
Therefore, children of married parents tend to suffer less poverty and material hardship than children of single or cohabiting parents (U.S. Census Bureau 2000; Smock 2000).

Growing up in a family of origin where psychological, physical, and/or sexual violence and victimization are present increases the risk that children will become both perpetrators and victims of intimate relationship violence. Psychological, physical, and sexual violence experienced in dating are associated with lower marital quality and divorce (Alleyne et al. 2011; Henry and Zeytinoglu 2012; Laporte et al. 2009). Dating violence is a reflection of a lack of healthy interactional skills.

Interactional processes are a function of couple traits and their interactional styles. Couple traits and interactional styles that influence marital satisfaction and dissatisfaction include communication and conflict resolution skills that incorporate cohesion and its associated components of intimacy, control or power sharing, and consensus (Larson 2003):

- Cohesion-a perception and feeling of emotional closeness as a result of finding a "balance" between time spent together as a couple and time spent apart

- Intimacy - the combination of self-disclosure, affection, sexual relations, and cohesion (i.e., a social, emotional, intellectual, physical, and often spiritual connection with a romantic partner) (Harris 2010)

- Control or power sharing-making decisions together that are perceived as equitable, fair, and respectful by both romantic partners

- Consensus - the degree to which couples perceive their values, beliefs, and interests are similar and the associated strategies they use to reach agreement, appreciate differences, and/or resolve conflict

\section{Conclusion}

Getting married and staying married require a complicated calculus of factors that must come together to produce healthy and satisfying relationships. While couple interactional processes tend to be the most predictive of whether or not they will stay together and find happiness, background and contextual factors and individual traits also factor heavily into the equation. Finding two socks that match (and don't wear out) is much more likely to occur when the relationship is based upon a deep and enduring friendship. Asking the question, "Will this choice enhance or diminish my marital friendship?" and then choosing to make the choices that will enhance the marital friendship more often than not are healthy strategies for success.

\section{References}

Alleyne, B., V. H. Coleman-Cowger, L. Crown, M. A. Gibbons, and L. N. Vines. 2011. The effects of dating violence, substance use and risky sexual behaviors among a diverse sample of Illinois youth. Journal of Adolescence, 34(1), 11-18.

Amato, P. R., D. R. Johnson, A. Booth, and S. J. Rogers. 2003. Continuity and change in marital quality between 1980 and 2000. Journal of Marriage and Family, 65(1), 1-22.

Brines, J., and K. Joyner. 1999. The ties that bind: Principles of cohesion in cohabitation and marriage. American Sociological Review, 64, 333-355.

Center for Disease Control and Prevention (CDC). 2012. Understanding teen dating violence. Online: http://www. dibbleinstitute.org/Documents/TeenDatingViolence2012-a. pdf

Dahl, G. B. 2010. Early teen marriage and future poverty. Demography, 47(3), 689-718.

Gottman, J. M. 1994a. Why marriages succeed or fail. New York: Fireside.

Gottman, J. M. 1994b. What predicts divorce? The relationship between marital process and marital outcomes. Hillsdale, NJ: Erlbaum.

Gottman, J. M., J. Coan, S. Carrere, and C. Swanson. 1998. Predicting marital happiness and stability from newlywed interactions. Journal of Marriage and Family, 60, 5-22.

Gottman, J. M., L. F. Katz, and C. Hooven. 1997. MetaEmotion: How families communicate emotionally. New Jersey: Erlbaum.

Gottman, J. M., and R. W. Levenson. 1999. Marital processes predictive of later dissolution: Behavior, physiology, and health. Journal of Personality and Social Psychology, 63, 221-233,

Gottman, J. M., and R. W. Levenson. 2000. The timing of divorce: Predicting when a couple will divorce over a 14year period. Journal of Marriage and Family, 62, 737-746. 
Harris, V. W. 2010. Marriage tips and traps: 10 secrets for nurturing your marital friendship. Plymouth, MI: Hayden-McNeil.

Harris, V. W., D. G. Schramm, J. P. Marshall, and T. R. Lee. 2012. Marital quality, context, and interaction: A comparison of those currently receiving government assistance with those who are not. Marriage \& Family Review, 48(4), 386-414.

Henry, R. R., and S. Zeytinoglu. 2012. African Americans and teen dating violence. American Journal of Family Therapy, 40(1), 20-32.

Holman, T. 2001. Premarital prediction of marital quality or breakup: Research, theory, and practice. New York, NY: Springer.

Jamison, T. B. and L. Ganong. 2011. "We're not living together": Stayover relationships among college-educated emerging adults. Journal of Social and Personal Relationships, 28(4), 536-557.

Johnson, C. A., S. M. Stanley, N. D. Glenn, P. R. Amato, S. L. Nock, H. J. Markman, et al. 2002. Marriage in Oklahoma: 2001 baseline statewide survey on marriage and divorce (S02096OKDHS). Oklahoma City, OK: Department of Human Services.

Karney, B. R., M. K. Beckett, R. L. Collins, and R. Shaw. 2007. Adolescent romantic relationships as precursors to healthy adult marriage-executive summary. Santa Monica, CA: Rand Corporation and The Department of Health and Human Services. Online: http://www.acf.hhs. gov/programs/opre/strengthen/marr_perscursors/reports/ adolescent_relationships/adolescent_relationships_0707. pdf

Laporte, L., D. Jiang, D. J. Pepler, and C. Chamberland. 2009. The relationship between adolescents' experience of family violence and dating violence. Youth and Society, $43(1), 2-27$.

Larson, J. H. 2003. The Great Marriage Tune-Up Book. San Francisco: Jossey-Bass.

Larson, J. H., and T. B. Holman. 1994. Predictors of marital quality and stability. Family Relations, 43, 228-237.

Mahoney, A., K. I. Pargament, N. Tarakeshwar, and A. B. Swank. 2001. Religion in the home in the 1980s and 1990s: A meta-analytic review and conceptual analysis of links between religion, marriage, and parenting. Journal of Family Psychology, 15(4), 559-596.

Marshall, J. P., D. G. Schramm, V. W. Harris, and T. R. Lee. In press. A comparison of premarital cohabiters vs. noncohabiters during their first year of marriage. Submitted to Family Science Review.

Miller, B. C. 1993. Families, science, and values: Alternative views of parenting effects and adolescent pregnancy. Journal of Marriage and the Family, 55, 7-21.

Murstein, B. I. 1986. Paths to marriage. Newbury Park, CA: Sage.

National Fatherhood Initiative. 2005. With this ring: $A$ national survey on marriage in America. Retrieved from http://www.smartmarriages.com/nms.pdf

Schramm, D. G., J. P. Marshall, V. W. Harris, and A. George. 2003. Marriage in Utah: 2003 baseline statewide survey on marriage and divorce. Salt Lake City: Utah Department of Workforce Services.

Schramm, D. G., and V. W. Harris. 2011. Marital quality and income: An examination of the influence of government assistance. Journal of Family and Economic Issues, 32, 437-448.

Smock, P. J. 2000. Cohabitation in the United States: An appraisal of research themes, findings, and implications. Annual Review of Sociology, 26, 1-20.

Teachman, J. 2003. Premarital sex, premarital cohabitation, and the risk of subsequent marital dissolution among women. Journal of Marriage and Family, 65(2), 444-455.

U.S. Census Bureau. 2000. Statistical abstract of the United States, 120 ed. Washington, DC: U.S. Government Printing Office.

Whitehead, B. D., and D. Popenoe. 2000. Sex without strings, relationships without rings. The State of our Unions, 2000 (pp. 6-20). Piscataway, NJ: The National Marriage Project, Rutgers University Press. Online: www. virginaia.edu/marriageproject/pdfs/print_sexwithoutstrings.pdf 